\title{
Comparison between local infiltration analgesia with combined femoral and sciatic nerve block for pain management after total knee arthroplasty
}

Yi Tian', Shuai Tang ${ }^{1 *} \mathbb{D}$, Sijin Sun ${ }^{1}$, Yuelun Zhang ${ }^{2}$, Lin Chen ${ }^{1}$, Di Xia ${ }^{1}$, Yingli Wang ${ }^{3}$, Liying Ren ${ }^{3}$ and Yuguang Huang ${ }^{1}$

\begin{abstract}
Background: Total knee arthroplasty (TKA) is usually associated with moderate to severe postoperative pain. Peripheral nerve block (PNB) and local infiltration analgesia (LIA) are two major methods for postoperative analgesia. Femoral nerve block (FNB) leads to residual posterior knee pain; thus, currently sciatic nerve block (SNB) and LIA are two major options for supplementing FNB. However, the efficacy and safety of LIA compared with combined femoral and sciatic nerve block still remain controversial. Here, we conducted a study to analyze the postoperative analgesic efficacy of these two methods.

Method: Two hundred six patients undergoing TKA were enrolled in a retrospective cohort study. The patients received either PNB or LIA. All patients in PNB group were conducted combined femoral and sciatic nerve block. All patients were encouraged to use patient-controlled analgesia (PCA) after surgery. The postoperative visual analog scale (VAS) at rest or with movement during the first $24 \mathrm{~h}$ and $48 \mathrm{~h}$ was recorded. We analyzed the VAS of $24 \mathrm{~h}$, VAS of $48 \mathrm{~h}$, opioid consumption, and adverse effects between PNB group and LIA group. Chi-square test and nonparametric test were used in this study.

Results: There were 82 patients in the PNB group and 124 patients in the LIA group. The patients' characteristics such as age, height, weight, and ASA showed no significant difference $(P>0.05)$. No significant differences were found $(P>0.05)$ between the two groups regarding VAS score at rest or with movement. The LIA group had less opioid consumption than the PNB group but without significant difference $(P>0.05)$. In both groups, the most common side effect was nausea, and the side effects showed no significant differences between groups $(P>0.05)$.

Conclusion: Local infiltration analgesia provided a similar analgesic effect and complications compared with combined femoral and sciatic nerve block in the short term. Considering less opioid consumption with local infiltration analgesia though without significant difference and its convenience, local infiltration analgesia provided better postoperative analgesia.
\end{abstract}

Keywords: Total knee arthroplasty, Peripheral nerve block, Local infiltration analgesia, Analgesia, Pain control

\footnotetext{
* Correspondence: tangshuaipumch@163.com

'Department of Anesthesiology, Peking Union Medical College Hospital,

CAMS\&PUMC, No.1, Wangfujing, DongCheng District, Beijing 100730, China

Full list of author information is available at the end of the article
}

(c) The Author(s). 2020 Open Access This article is distributed under the terms of the Creative Commons Attribution 4.0 International License (http://creativecommons.org/licenses/by/4.0/), which permits unrestricted use, distribution, and reproduction in any medium, provided you give appropriate credit to the original author(s) and the source, provide a link to the Creative Commons license, and indicate if changes were made. The Creative Commons Public Domain Dedication waiver (http://creativecommons.org/publicdomain/zero/1.0/) applies to the data made available in this article, unless otherwise stated. 


\section{Introduction}

Total knee arthroplasty (TKA) is one of the most popular treatments for chronic refractory knee pain and loss of function caused by different underlying knee disorders [1]. Total knee arthroplasty is associated with serious postoperative pain, and many patients report moderate to severe pain even past the anticipated recovery period, which is a major problem that surgeons need to address [2, 3]. Inadequate postoperative pain management can lead to acute effects, including immune system suppression, decreased mobility, and increased risk for deep vein thrombosis and pulmonary embolism $[4,5]$. Most of all, poor pain management results in patient's reluctance to mobilize the joint, hence poor functional recovery after surgery [6].

There are several methods available for postoperative analgesia including systemic opioids, continuous peripheral nerve block, peripheral nerve block, and local infiltration analgesia. Peripheral nerve block (PNB), including different techniques such as femoral nerve block, sciatic nerve block, and adductor canal block (ACB) [7], is the mainstream treatment for postoperative pain following TKA [8]. Local infiltration analgesia (LIA) was introduced to clinical practice in recent years and has been found to be helpful in relieving acute pain after TKA $[9,10]$. It is performed by the surgeon at the end of the procedure and has fewer side effects of muscular weakness, offering earlier mobilization $[11,12]$.

Currently, both femoral nerve block (FNB) and local infiltration anesthesia (LIA) can provide effective analgesia, facilitate early mobilization, and reduce the length of hospital stay $[13,14]$. Previous research has shown that some patients experience significant postoperative pain despite the use of FNB $[15,16]$, due to the fact that the posterior part of the knee is innervated by the sciatic nerve. Since LIA is an alternative, convenient anesthetic technique that is usually performed by orthopedic surgeons [10, 17], anesthesia via FNB combined with sciatic nerve block (SNB) and LIA are two major options for supplementing FNB to relieve pain after TKA $[18,19]$. Recent studies have shown that SNB has similar anesthesia effects and opioid consumption than LIA when combined with FNB $[20,21]$.. However, there are few studies focusing on the comparison between LIA with combined femoral and sciatic nerve block; thus, no consensus regarding LIA versus SNB and FNB were reached. Our study aims to evaluate the analgesic effect and complication of local infiltration analgesia compared with combined femoral and sciatic nerve block after TKA. We hypothesized that local infiltration analgesia has similar analgesic effect compared with combined femoral and sciatic nerve block.

\section{Methods}

We performed a retrospective cohort study. The Institutional Review Board (IRB) at Peking Union Medical
College Hospital (PUMCH) approved this study (\#SK422). We queried hospital anesthesia records to identify all patients who were scheduled for unilateral TKA from January 2013 to December 2016. The inclusion criteria were as follows: patients for unilateral elective total knee arthroplasty, under combined femoral and sciatic nerve block or local infiltration analgesia, American Society of Anesthesiologists (ASA) classification I-III (American Society of Anesthesiologists functional status), and more than 18 years old. We excluded patients with incomplete information, who were unable to cooperate or refuse to participation, and who had an allergy to any drug administered in the study.

TKA was all performed through midline vertical incision and medial parapatellar approach by two chief surgeons who were highly experienced. All patients received general anesthesia during surgery with standard drugs. In the PNB group, patients preoperatively received ultrasound-guided combined femoral and sciatic block by two anesthesiologists. $0.5 \%$ plain ropivacaine was injected to the desired sonographic anatomical location. In the LIA group, patients received $50 \mathrm{ml}$ of cocktail mixture containing $30 \mathrm{ml}$ ropivacaine $(10 \mathrm{mg} / \mathrm{ml})$, $0.5 \mathrm{ml}$ morphine $(10 \mathrm{mg} / \mathrm{ml}), 1 \mathrm{ml}$ diprospan $(5 \mathrm{mg} / \mathrm{ml})$, and normal saline to make up to $50 \mathrm{ml}$. This solution was infiltrated into the joint capsule in particular the posterior capsule, retinacular tissue, subcutaneous tissues, and anterior fat pad. Patients in PNB group received no injection. The LIA procedure was conducted by two chief surgeons after the main step of the surgery.

After surgery, all patients received a standard postoperative regimen of parecoxib (Dynastat ${ }^{\oplus}$, Pfizer) $40 \mathrm{mg}$ bid for 3 days as well as an intravenous patientcontrolled analgesia (PCA) pump for $48 \mathrm{~h}$. PCA pump was morphine 40-60 mg in normal saline $250 \mathrm{ml}$, which was programmed to give a background dose of $0-4 \mathrm{ml} /$ h, a 3-4-ml bolus on demand, a lock-out time of 10-15 min, and a maximum dose of $40-60 \mathrm{ml} / 4 \mathrm{~h}$. All patients were encouraged to use PCA as often as needed. The PCA record of each patient was monitored and administered in the Department of Anesthesiology which can be searched through intranet or the medical record.

\section{Outcomes: pain scores}

All patients were educated preoperatively by the Acute Pain Service team about pain assessment using a visual analog scale (VAS): $0=$ no pain and $10=$ worst pain imaginable. VAS scores at rest or with movement during the first $24 \mathrm{~h}$ and $48 \mathrm{~h}$ once a day were recorded by the specialists of Acute Pain Service team [22] before physical therapy during hospitalization. No data were imputed for the primary outcome if the patient was asleep or unable to report VAS. 


\section{Side effects}

Complications including nausea and vomiting, pruritus, and sedation were recorded. The VAS score and complications were administered in the department of anesthesiology which can be searched through intranet. And it was also documented in the medical record of each patient.

\section{Statistical analysis}

We described the baseline characteristics of patients in the PNB and LIA groups in tabular form. The difference of baseline characteristics between the PNB and LIA groups were compared, and factors with $P$ value less than 0.1 were regarded as potential confounders. Based on the non-normally distribution of the main outcomes including VAS on rest, VAS with movement, and PCA consumption, they were compared using Mann-Whitney test between the PNB and LIA groups. If there were unbalanced baseline characteristics between groups, the main outcomes were further analyzed stratified by the confounders. Side effects in the PNB and LIA groups were compared using the chi-squared test. As sex was an important impact factor for postoperative nausea and vomiting (PONV), the difference of the side effects between groups was further striated and adjusted using logistic regression by sex. A two-side $P$ value less than 0.05 was considered statistically significant. Statistical analyses were done in the STATA software (Version 14.1[StataCorp., 4905 Lakeway College Station, TX 77845, USA]).

\section{Results}

A total of 254 patients were reviewed using the electronic medical records system. There were 46 patients in the PNB group and 2 patients in the LIA group who received continuous peripheral nerve block, which were excluded. Finally, 206 patients were included for analysis. For the PNB group, 82 patients were identified, all of which received combined femoral and sciatic nerve block. For the LIA group, 124 patients were identified. Patient demographics are shown in Table 1. There are no statistical differences between the two groups.

Regarding pain management, there was no significant difference $(P>0.05)$ between the two groups on VAS score at rest or with movement during the first $24 \mathrm{~h}$ and $48 \mathrm{~h}$ (Table 2). The LIA group had less PCA consumption than the PNB group on POD1 (33.74 vs. $33.62, P=$ 0.86 ) and POD2 (24.88 vs. $28.45, P=0.55$ ), but without significant difference (Table 2). The trend of opioids consumption is shown in Fig. 1.

In both groups, nausea was the most common side effect on POD1 and POD2 (13-31\%), followed by vomiting $(2-18 \%)$, sedation $(3-13 \%)$, and pruritus $(1-3 \%)$. The side effects including nausea, vomiting, pruritus,
Table 1 Patient demographics

\begin{tabular}{llll}
\hline Items & PNB $(N=82)$ & LIA $(N=124)$ & $P$ value \\
\hline Gender & & & 0.10 \\
$\quad$ Male & $16(19.51 \%)$ & $37(29.84 \%)$ & \\
Age & $66(80.49 \%)$ & $87(70.16 \%)$ & \\
Height & $67.1(9.4)$ & $65.8(12.6)$ & 0.40 \\
Weight & $161.5(6.4)$ & $162.0(8.4)$ & 0.70 \\
BMI & $68.8(8.9)$ & $69.4(12.0)$ & 0.70 \\
ASA & $26.4(3.3)$ & $26.5(4.3)$ & 0.85 \\
I & & & 0.57 \\
II & $6(7.32 \%)$ & $14(11.29 \%)$ & \\
III & $66(80.49 \%)$ & $98(79.03 \%)$ & \\
\hline
\end{tabular}

Baseline characteristics presented as number (\%) or mean (standard deviation) $P N B$ peripheral nerve block, LIA local infiltration analgesia

and sedation have similar occurrence rates. Notably, nausea and vomiting on day 2 were significantly more common in the PNB group compared with the LIA group $(P=0.02)$. However, after controlling for or being striated by gender between these two groups, which is a well-known risk factor for nausea and vomiting [23], the difference was not statistically significant. The details of the side effects are presented in Table 3.

\section{Discussion}

The present study was aimed to compare the effects and safety of PNB and LIA. After analyzing VAS, morphine consumptions, and side effects, the results indicate that LIA has similar postoperative analgesic efficacy and complications than combined femoral and sciatic nerve block. Thus, we believe that LIA is as effective and safe as PNB.

Adequate pain relief after TKA is important as it enhances rehabilitation [24, 25], which is of key importance for a satisfactory outcome. In our study, postoperative pain is managed in a multimodal style including PNB or LIA followed by intravenous PCA within the first 2 days after surgery. VAS both at rest and with movement was

Table 2 VAS and PCA of the two groups

\begin{tabular}{llll}
\hline Items & PNB $(N=82)$ & LIA $(N=124)$ & $P$ value \\
\hline Day 1 VAS on rest & 1.35 & 1.35 & 0.95 \\
Day 2 VAS on rest & 0.73 & 0.85 & 0.42 \\
Day 1 VAS with movement & 3.25 & 3.16 & 0.82 \\
Day 2 VAS with movement & 2.55 & 2.47 & 0.80 \\
Day 1 PCA consumption & 33.62 & 33.74 & 0.86 \\
Day 2 PCA consumption & 28.45 & 24.88 & 0.55
\end{tabular}

Outcomes: VAS on rest, VAS with movement, and PCA consumption presented as mean

$P N B$ peripheral nerve block, LIA local infiltration analgesia, VAS visual analog scale, $P C A$ patient-controlled analgesia 


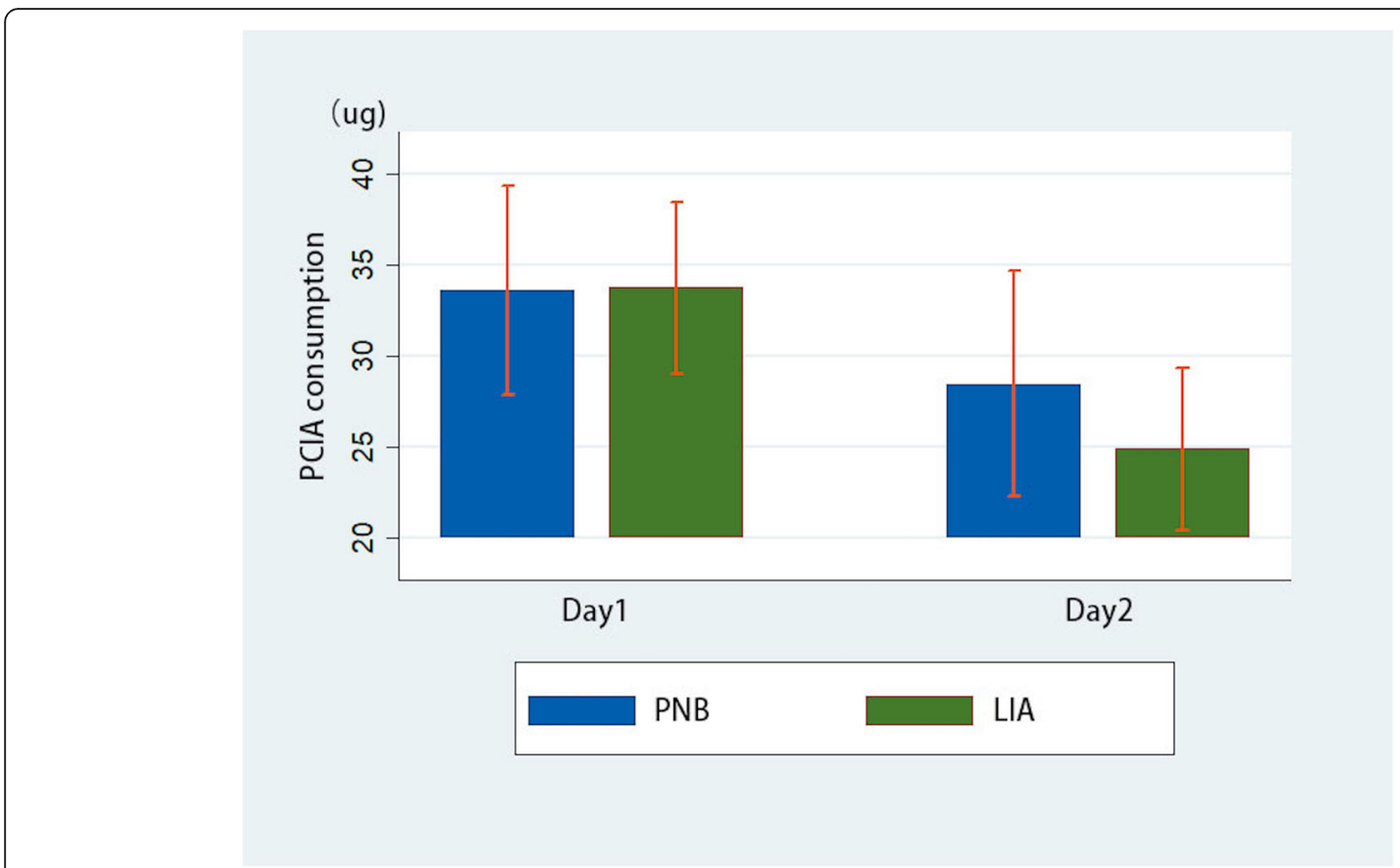

Fig. 1 Trend of opioids consumption postoperative between groups

evaluated. Postoperative VAS remained at a low level in both groups; thus, sufficient postoperative analgesia was achieved with either PNB or LIA technique. We found no significant difference between the two groups on VAS at rest or with movement during the first $24 \mathrm{~h}$ and $48 \mathrm{~h}$, which indicates that the pain relief effect of both methods is comparable. The reason for this is due to the multimodal analgesia including PCA pump and LIA which make patients in an acceptable range of pain, thus resulting in a similar degree of pain relief. As for all kinds of peripheral nerve block, LIA has similar pain relief compared with single femoral nerve block [26, 27], continuous femoral nerve block [27, 28], and single sciatic nerve block $[18,20]$. However, currently, few studies focus on the comparison between local infiltration analgesia with combined femoral and sciatic nerve block and do not reach a consensus. One of them has the same results as pain relief was similar between the two groups [29, 30]; other studies indicate that FNB combined with SNB provides superior pain relief than LIA [31, 32]. Therefore, this study enriches existing literatures in this field of comparing combined femoral and sciatic nerve block.

Although the pain scores were similar in the two groups, the LIA group $(24.88 \mathrm{mg}$ ) had less PCA consumption than the PNB group (28.45 mg) up to $48 \mathrm{~h}$ postoperatively. Opioid consumption is considered an objective method of measuring pain. The tendency of lower efficacy with femoral and sciatic block may be due to the fact that some part of the knee is innervated by the other nerves such as the obturator nerve [33, 34] and some cutaneous nerve [35] which are still not blocked. Thus, a peripheral nerve block may need supplementary treatment with more systemic analgesics such as opioids and NSAIDs [32]. Another explanation why LIA is more effective might be the better effect of nerve block of the intraarticular drugs [36]. Analgesic effect of NSAIDs is better after intraarticular administration than after systemic IV injection [37]. The reduction in PCA consumption from POD1 to POD2 is larger in the LIA group ( $8.86 \mathrm{mg}$ ) compared with the PNB group $(5.17 \mathrm{mg})$, which indicates that the effect of peripheral nerve block may be shorter than LIA. It can be interpreted by the long-lasting anti-inflammatory effect of diprospan locally and systemically, which were confirmed in the past study [38].

The incidence of side effects was similar between the two groups. Opioid-related adverse effects such as postoperative nausea and vomiting, antiemetic use, and postoperative sedation/drowsiness were reported in previous studies [39, 40], but we did not find significant differences between the two groups in this study. This could be because the difference between the two groups in PCA consumption was not large enough to cause sufficient differences in side effects. It is possible that side effects of opioids are dose dependent [40] and that when larger doses are administered, the incidence of side effects increases and then becomes more clinically significant.

LIA is a relatively safe operation. LIA is performed by injecting analgesic drugs into the soft tissues around the surgical site including both the anterior and posterior 
Table 3 Details of the side effects

\begin{tabular}{|c|c|c|c|c|c|c|c|c|c|}
\hline \multirow[t]{2}{*}{ Items } & \multicolumn{3}{|l|}{ Total } & \multicolumn{3}{|l|}{ Male } & \multicolumn{3}{|l|}{ Female } \\
\hline & PNB & LIA & $P$ value & PNB & LIA & $P$ value & PNB & LIA & $P$ value \\
\hline Day 1 nausea & & & 0.07 & & & 0.59 & & & 0.16 \\
\hline Yes & $26(32 \%)$ & 25 (20\%) & & $2(17 \%)$ & $4(11 \%)$ & & 24 (34\%) & 21 (25\%) & \\
\hline No & $56(68 \%)$ & 99 (80\%) & & $10(73 \%)$ & 33 (89\%) & & 46 (66\%) & $66(75 \%)$ & \\
\hline Day 1 vomit & & & 0.08 & & & 0.43 & & & 0.31 \\
\hline Yes & $14(18 \%)$ & $13(10 \%)$ & & $1(8 \%)$ & $1(3 \%)$ & & $13(20 \%)$ & $12(14 \%)$ & \\
\hline No & $64(82 \%)$ & 111 (90\%) & & $12(92 \%)$ & $36(97 \%)$ & & 52 (80\%) & 75 (86\%) & \\
\hline Day 1 pruritus & & & 0.90 & & & 0.54 & & & 0.69 \\
\hline Yes & $2(3 \%)$ & $3(3 \%)$ & & $0(0 \%)$ & $1(3 \%)$ & & $2(4 \%)$ & $2(2 \%)$ & \\
\hline No & $68(97 \%)$ & 117 (97\%) & & $13(100 \%)$ & 35 (97\%) & & 55 (96\%) & 82 (98\%) & \\
\hline Day 1 sedation & & & 0.20 & & & 0.86 & & & 0.22 \\
\hline Yes & $10(13 \%)$ & $9(7 \%)$ & & $1(7 \%)$ & $2(5 \%)$ & & $9(14 \%)$ & $7(8 \%)$ & \\
\hline No & $68(87 \%)$ & 115 (93\%) & & $14(93 \%)$ & 35 (95\%) & & $54(86 \%)$ & 80 (92\%) & \\
\hline Day 2 nausea & & & 0.02 & & & 0.12 & & & 0.09 \\
\hline Yes & $21(26 \%)$ & $16(13 \%)$ & & $3(25 \%)$ & $3(8 \%)$ & & $18(26 \%)$ & $13(15 \%)$ & \\
\hline No & $61(74 \%)$ & 108 (87\%) & & $9(75 \%)$ & $34(92 \%)$ & & $52(74 \%)$ & 74 (75\%) & \\
\hline Day 2 vomit & & & 0.05 & & & 0.13 & & & 0.91 \\
\hline Yes & $6(8 \%)$ & $12(10 \%)$ & & $2(13 \%)$ & $2(5 \%)$ & & $4(6 \%)$ & 10 (11\%) & \\
\hline No & 71 (92\%) & 112 (90\%) & & $13(87 \%)$ & 35 (95\%) & & 58 (74\%) & 77 (89\%) & \\
\hline Day 2 pruritus & & & 0.77 & & & - & & & 0.85 \\
\hline Yes & $1(1 \%)$ & $1(0 \%)$ & & $0(0 \%)$ & $0(0 \%)$ & & $1(2 \%)$ & $1(1 \%)$ & \\
\hline No & 69 (99\%) & 105 (100\%) & & $13(100 \%)$ & $35(100 \%)$ & & $56(98 \%)$ & 73 (99\%) & \\
\hline Day 2 sedation & & & 0.20 & & & 0.85 & & & 0.10 \\
\hline Yes & $5(6 \%)$ & $3(3 \%)$ & & $1(7 \%)$ & $2(6 \%)$ & & $4(6 \%)$ & $1(1 \%)$ & \\
\hline No & 72 (94\%) & 111 (97\%) & & $13(93 \%)$ & 33 (94\%) & & $58(94 \%)$ & 78 (99\%) & \\
\hline
\end{tabular}

Side effects on POD1and 2 including nausea, vomiting, urinary retention, pruritus, and sedation presented as number (\%) $P N B$ peripheral nerve block, LIA local infiltration analgesia

knee capsules [41]. There were no previous literatures reporting medical complications of LIA because there are no large blood vessels and nerves in the surgery area.

The limitation of this study comes from the retrospective design. Our study is a single-center clinical trial, and selective bias is inevitable. Second, due to the limitation of study design, we cannot compare functional outcomes and long-term outcomes between groups. Nikolajsen et al. reported that more than $12 \%$ of patients had moderate to severe postoperative pain even more than a year after operation [42]. Even more, more than twice as many patients have chronic pain after revision TKA surgery compared with primary TKA [43]. But our study focused on the short-term outcome at $48 \mathrm{~h}$ after surgery instead of chronic pain. Therefore, multicenter studies focusing on functional outcome and long-term pain management are needed in the future.

In conclusion, local infiltration analgesia provided a similar analgesic effect and complications compared with combined femoral and sciatic nerve block in the short term. LIA is a relatively convenient and easy method compared with nerve block, which can be administered without the need for specialist additional equipment. Thus, LIA should be considered as a viable and safe alternative to combined femoral and sciatic nerve block for early pain relief following TKA, especially in developing countries where LIA has not been widely applied.

\section{Abbreviations}

ACB: Adductor canal block; ASA: American Society of Anesthesiologists; LIA: Local infiltration analgesia; PCA: Patient-controlled analgesia; PNB: Peripheral nerve block; TKA: Total knee arthroplasty; VAS: Visual analog scale

\section{Acknowledgements}

We would like to thank Dr. Haobo Ma and Simon Zhang, PhD, MD, from the Department of Anesthesia in Beth Israel Deaconess Medical Center, Harvard Medical School, for revising and proofreading the manuscript.

\section{Authors' contributions}

ST and Y-GH designed the study. ST, YT, LC, DX, Y-LW, and L-YR collected the clinical data. $Y T$ and S-JS completed the data analysis. $Y$ - LZ proofread the statistics. ST and YT wrote the manuscript. All authors read and approved the final manuscript. 


\section{Funding}

None of the authors has received or will receive benefits for personal or professional use from a commercial party related directly or indirectly to the subject of this article.

\section{Availability of data and materials}

The datasets generated and analyzed during the current study are available from the corresponding author on reasonable request.

\section{Ethics approval and consent to participate}

The Institutional Review Board (IRB) at Peking Union Medical College Hospital (PUMCH) approved this study (\#S-K422). Consent to participate was not obtained from each participant.

\section{Consent for publication}

Not applicable.

\section{Competing interests}

The authors declare that they have no competing interests.

\section{Author details}

'Department of Anesthesiology, Peking Union Medical College Hospital, CAMS\&PUMC, No.1, Wangfujing, DongCheng District, Beijing 100730, China. ${ }^{2}$ Central Research Laboratory, Peking Union Medical College Hospital, Chinese Academy of Medical Sciences and Peking Union Medical College, No.1, Wangfujing, DongCheng District, Beijing 100730, China. ${ }^{3}$ Operating Room, Peking Union Medical College Hospital, Chinese Academy of Medical Sciences, Beijing 100730, China.

\section{Received: 31 July 2018 Accepted: 30 January 2020}

\section{Published online: 07 February 2020}

\section{References}

1. Harris WH, Sledge CB. Total hip and total knee replacement. N Engl J Med. 1990;323:801-7.

2. Hadlandsmyth $\mathrm{K}$, Zimmerman $M$, Wajid $R$, et al. Longitudinal postoperative course of pain and dysfunction following total knee arthroplasty. Clin J Pain. 2018;34:332-8

3. Beswick AD, Wylde V, Gooberman-Hill R, Blom A, Dieppe P. What proportion of patients report long-term pain after total hip or knee replacement for osteoarthritis? A systematic review of prospective studies in unselected patients. BMJ Open. 2012;2:e000435.

4. Baratta JL, Schwenk ES, Viscusi ER. Clinical consequences of inadequate pain relief: barriers to optimal pain management. Plast Reconstr Surg. 2014;134: 15S-21S.

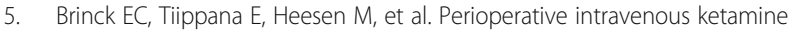
for acute postoperative pain in adults. Cochrane Database Syst Rev. 2018;12: CD012033.

6. Erlenwein J, Przemeck M, Degenhart A, et al. The influence of chronic pain on postoperative pain and function after hip surgery: a prospective observational cohort study. J Pain. 2016;17:236-47.

7. Li D, Yang Z, Xie X. Adductor canal block provides better performance after total knee arthroplasty compared with femoral nerve block: a systematic review and meta-analysis. Int Orthop. 2016;40:925-33.

8. Gaffney CJ, Pelt CE, Gililland JM, Peters CL. Perioperative pain management in hip and knee arthroplasty. Orthop Clin North Am. 2017;48:407-19.

9. Seangleulur A, Vanasbodeekul P, Prapaitrakool S, et al. The efficacy of local infiltration analgesia in the early postoperative period after total knee arthroplasty: a systematic review and meta-analysis. Eur J Anaesthesiol. 2016; 33:816-31.

10. Kurosaka K, Tsukada S, Seino D, Morooka T, Nakayama H, Yoshiya S. Local infiltration analgesia versus continuous femoral nerve block in pain relief after total knee arthroplasty: a randomized controlled trial. J Arthroplast. 2016;31:913-7.

11. Mulford JS, Watson A, Broe D, Solomon M, Loefler A, Harris I. Short-term outcomes of local infiltration anaesthetic in total knee arthroplasty: a randomized controlled double-blinded controlled trial. ANZ I Surg. 2016;86: 152-6.

12. Sun $X L$, Zhao $Z H$, Ma JX, et al. Continuous local infiltration analgesia for pain control after total knee arthroplasty: a meta-analysis of randomized controlled trials. Medicine (Baltimore). 2015;94:e2005.
13. Albrecht E, Guyen O, Jacot-Guillarmod A, Kirkham K. The analgesic efficacy of local infiltration analgesia vs femoral nerve block after total knee arthroplasty: a systematic review and meta-analysis. Br J Anaesth. 2016;116: 597-609.

14. Nakagawa S, Arai Y, Inoue $H$, et al. Comparative effects of periarticular multimodal drug injection and single-shot femoral nerve block on pain following total knee arthroplasty and factors influencing their effectiveness. Knee Surg Relat Res. 2016;28:233-8.

15. Davies A, Segar E, Murdoch J, Wright D, Wilson I. Epidural infusion or combined femoral and sciatic nerve blocks as perioperative analgesia for knee arthroplasty. Br J Anaesth. 2004;93:368-74.

16. Bullingham A, Liang S, Edmonds E, Mathur S, Sharma S. Continuous epidural infusion vs programmed intermittent epidural bolus for labour analgesia: a prospective, controlled, before-and-after cohort study of labour outcomes. Br J Anaesth. 2018;121:432-7.

17. Ashraf A, Raut W, Canty SJ, McLauchlan GJ. Pain control after primary total knee replacement. A prospective randomised controlled trial of local infiltration versus single shot femoral nerve block. Knee. 2013;20:324-7.

18. Tanikawa $\mathrm{H}$, Harato $\mathrm{K}$, Ogawa $\mathrm{R}$, et al. Local infiltration of analgesia and sciatic nerve block provide similar pain relief after total knee arthroplasty. J Orthop Surg Res. 2017;12:109-14.

19. Albrecht $E$, Guyen O, Jacot-Guillarmod A. The analgesic efficacy of sciatic nerve block in addition to femoral nerve block in patients undergoing total knee arthroplasty: a systematic review and meta-analysis. Anaesthesia. 2016; 71:1198-209.

20. Li J, Deng X, Jiang T. Combined femoral and sciatic nerve block versus femoral and local infiltration anesthesia for pain control after total knee arthroplasty: a meta-analysis of randomized controlled trials. J Orthop Surg Res. 2016;11:158-71.

21. Spangehl M, Clarke H, Hentz J, Misra L, Blocher J, Seamans D. The Chitranjan Ranawat Award: periarticular injections and femoral \& sciatic blocks provide similar pain relief after TKA: a randomized clinical trial. Clin Orthop Relat Res. 2015;473:45-53.

22. Tong QJ, Lim YC, Tham HM. Comparing adductor canal block with local infiltration analgesia in total knee arthroplasty: a prospective, blinded and randomized clinical trial. J Clin Anesth. 2018:46:39-43.

23. Teunkens $A$, Vanhaecht $K$, Vermeulen $K$, et al. Measuring satisfaction and anesthesia related outcomes in a surgical day care centre: a three-year single-centre observational study. J Clin Anesth. 2017;43:15-23.

24. Elmallah RK, Cherian JJ, Pierce TP. New and common perioperative pain management techniques in total knee arthroplasty. J Knee Surg. 2016;29: 169-78.

25. van Haagen MHM, Verburg H, Hesseling B, et al. Optimizing the dose of local infiltration analgesia and gabapentin for total knee arthroplasty, a randomized single blind trial in 128 patients. Knee. 2018;25:153-60.

26. Zhang LK, Ma JX, Kuang MJ. Comparison of periarticular local infiltration analgesia with femoral nerve block for total knee arthroplasty: a metaanalysis of randomized controlled trials. J Arthroplast. 2018;33:1972-8.

27. Choi S, O'Hare T, Gollish J, et al. Optimizing pain and rehabilitation after knee arthroplasty: a two-center, randomized trial. Anesth Analg. 2016;123: 1316-24.

28. Pizzi LT, Toner R, Foley K. Multimodal periarticular injection vs continuous femoral nerve block after total knee arthroplasty: a prospective, crossover, randomized clinical trial. J Arthroplast. 2012;27:1234-8.

29. Berninger $M$, Friederichs J, Leidinger $W$, et al. Effect of local infiltration analgesia, peripheral nerve blocks, general and spinal anesthesia on early functional recovery and pain control in unicompartmental knee arthroplasty. BMC Musculoskelet Disord. 2018;19:249-58.

30. Safa B, Gollish J, Haslam L. Comparison of local infiltration of analgesia and sciatic nerve block in addition to femoral nerve block for total knee arthroplasty. J Arthroplast. 2014;29:2462-7.

31. Ma LP, Qi YM, Zhao DX. Comparison of local infiltration analgesia and sciatic nerve block for pain control after total knee arthroplasty: a systematic review and meta-analysis. J Orthop Surg Res. 2017;12:85-96.

32. Nagafuchi M, Sato T, Sakuma T, et al. Femoral nerve block-sciatic nerve block vs. femoral nerve block-local infiltration analgesia for total knee arthroplasty: a randomized controlled trial. BMC Anesthesiol. 2015;15:182-8.

33. Runge $C$, Jensen JM, Clemmesen $L$, et al. Analgesia of combined femoral triangle and obturator nerve blockade is superior to local infiltration analgesia after total knee arthroplasty with high-dose intravenous dexamethasone. Reg Anesth Pain Med. 2018;43:352-6. 
34. Kampitak W, Tanavalee A, Ngarmukos S. Opioid-sparing analgesia and enhanced recovery after total knee arthroplasty using combined triple nerve blocks with local infiltration analgesia. J Arthroplast. 2019;34:295-302.

35. Sogbein OA, Sondekoppam RV, Bryant D, et al. Ultrasound-guided motorsparing knee blocks for postoperative analgesia following total knee arthroplasty: a randomized blinded study. J Bone Joint Surg Am. 2017;99: 1274-81.

36. Rømsing J, Møiniche S, Ostergaard D, Dahl J. Local infiltration with NSAIDs for postoperative analgesia: evidence for a peripheral analgesic action. Acta Anaesthesiol Scand. 2000;44:672-83.

37. Spreng U, Dahl V, Hjall A, Fagerland M, Ræder J. High-volume local infiltration analgesia combined with intravenous or local ketorolac+ morphine compared with epidural analgesia after total knee arthroplasty. $\mathrm{Br}$ J Anaesth. 2010;105:675-82.

38. Ikeuchi M, Kamimoto $Y$, Izumi M, et al. Effects of dexamethasone on local infiltration analgesia in total knee arthroplasty: a randomized controlled trial. Knee Surg Sports Traumatol Arthrosc. 2014;22:1638-43.

39. Sehmbi H, Brull R, Shah UJ, et al. Evidence basis for regional anesthesia in ambulatory arthroscopic knee surgery and anterior cruciate ligament reconstruction: part II: adductor canal nerve block-a systematic review and meta-analysis. Anesth Analg. 2019;128:223-38.

40. Pizzi LT, Toner R, Foley K, et al. Relationship between potential opioidrelated adverse effects and hospital length of stay in patients receiving opioids after orthopedic surgery. Pharmacotherapy. 2012;32:502-14.

41. Ong JC, Chin PL, Fook-Chong SM. Continuous infiltration of local anaesthetic following total knee arthroplasty. J Orthop Surg (Hong Kong). 2010;18:203-7.

42. Toftdahl K, Nikolajsen L, Haraldsted V, Madsen F, Tonnesen EK, Soballe K Comparison of peri- and intraarticular analgesia with femoral nerve block after total knee arthroplasty: a randomized clinical trial. Acta Orthop. 2007; 78:172-9.

43. Petersen $\mathrm{K}$, Simonsen $\mathrm{O}$, Laursen M, Nielsen T, Rasmussen S, Arendt-Nielsen L. Chronic postoperative pain after primary and revision total knee arthroplasty. Clin J Pain. 2015;31:1-6.

\section{Publisher's Note}

Springer Nature remains neutral with regard to jurisdictional claims in published maps and institutional affiliations.

Ready to submit your research? Choose BMC and benefit from:

- fast, convenient online submission

- thorough peer review by experienced researchers in your field

- rapid publication on acceptance

- support for research data, including large and complex data types

- gold Open Access which fosters wider collaboration and increased citations

- maximum visibility for your research: over $100 \mathrm{M}$ website views per year

At $\mathrm{BMC}$, research is always in progress.

Learn more biomedcentral.com/submissions 